\title{
Risk of idiopathic nephrotic syndrome among children with asthma: a nationwide, population-based cohort study
}

\author{
Chang-Ching Wei ${ }^{1,2}$, Cheng-Li Lin ${ }^{3,4}$, Te-Chun Shen ${ }^{2,5}$ and Yu-Fen Li ${ }^{4}$
}

BACKGROUND: Although clinical and immunological studies have shown a possible link between allergy and idiopathic nephrotic syndrome (INS), the nature of the relationship remains unclear. Asthma is the most common chronic allergic airway inflammation. However, no study has used a longitudinal design with a population cohort to investigate INS in children with asthma.

METHODS: Using nationwide claims data from 2000 through 2007, we randomly selected 251,698 asthma cases and $1,006,791$ frequency-matched controls. Incidence rates of INS and hazard ratios (HRs) were calculated.

RESULTS: The INS incidence was 3.36-fold greater in the asthma cohort than in the nonasthma control (9.26 vs. 2.76 per 100,000 person-years; 95\% confidence interval (Cl): 2.65-4.26). The HR for INS increased for those with more asthma-related medical visits per year, from 1.49 (95\% Cl: 1.06-2.11) for $<3$ visits to 15.7 (95\% Cl: $11.5-21.5$ ) for $\geq 6$ visits (trend test, $P<0.0001$ ). The HR for INS slightly decreased during the follow-up period, from 3.41 (95\% Cl: $2.66-4.38$ ) for $\leq 5.5$ y to 2.90 (95\% Cl: $1.33-$ 6.30) for $>5.5 \mathrm{y}$.

CONCLUSION: We conclude that children with asthma had an increased incidence rate of INS, and increased incidence rate correlated with asthma-related medical visits.

diopathic nephrotic syndrome (INS) is among the most common chronic kidney diseases occurring in childhood (1). Numerous studies have associated INS with allergy risk of clinical and immunological features (2-11). In the 1950s through the 1970s, few anecdotal reports described patients who developed INS after allergic reactions to inhaled allergens, vaccinations, food, or insect stings (2-5). Since 1970, several case-control studies revealed that elevated serum IgE and atopic diathesis were more common in children with INS than non-INS controls (9,11-17). Recently, levels of T helper 2 (Th2)-associated cytokine such as interleukin (IL)-4 and IL-13 were found to be elevated in relapsing INS patients (18-21). Children with INS commonly have elevated serum levels of immunoglobulin $\mathrm{E}$ (IgE), which also plays a central role in allergic inflammation (11-16). Although clinical and immunological studies have shown a possible link between allergic diseases and INS for $50 \mathrm{y}$, human epidemiologic study using a large cohort to investigate the relationship between these disorders are lacking (2-11). Asthma is one of the most common allergic disease in childhood, affects a multitude of patients worldwide (22). It is unknown whether childhood onset asthma would increase the subsequent risk of INS. Therefore, we conducted a nationwide, population-based cohort study to examine the hypothesis that asthma may have positive influence on the development of INS in children.

\section{RESULTS}

A total of 251,698 subjects in the asthma cohort and 1,006,791 in the nonasthma cohort were enrolled in this study (Table 1 ). Most (67.6\%) of the subjects were aged $\leq 5 \mathrm{y}$. The asthma cohort had more boys (59.4\%), residents of highly urbanized areas (59.8\%), and white-collar parents (64.6\%). Figure 1 illustrates the INS-free survival rate of the asthma cohort compared with that of the nonasthma cohort. The INS-free survival rate (Figure 1a, log-rank test $P<0.0001$ ) was significantly lower in the asthma cohort in the nonasthma cohort. The incidence of INS was 3.36-fold greater in the asthma cohort than in the nonasthma cohort ( 9.26 vs. 2.76 per 100,000 person-years; Table 2). The incidence of INS decreased as age increased in the nonasthma cohort, whereas the incidence increased when age was $<2$ y or $>12 y$ in the asthma cohort. As age increased, the HR for INS increased from 2.89 (95\% CI: 1.87-4.47) for subjects aged $\leq 2$ y to 5.59 (95\% CI: 1.77-17.6) for those aged $>12 \mathrm{y}$. A sex-specific analysis showed that the incidence rate of INS was greater for boys in both cohorts. Girls with asthma had a greater risk of INS than those without asthma $(\mathrm{HR}=3.82 ; 95 \% \mathrm{CI}: 2.59-5.64)$. The INS incidence decreased with urbanization in the asthma cohort. Urbanization leveland parental occupation-specific analyses showed that children with asthma had a significantly greater risk of INS than those without asthma. Table 3 shows the association between the frequency of medical visits per year for asthma and the incidence of INS. Compared with the nonasthma cohort, the

\footnotetext{
'Department of Nephrology, Children's Hospital, China Medical University Hospital, Taichung, Taiwan; ${ }^{2}$ College of Medicine, China Medical University, Taichung, Taiwan; ${ }^{3}$ Management Office for Health Data, China Medical University Hospital, Taichung, Taiwan; ${ }^{4}$ Institute of Biostatistics, China Medical University, Taichung, Taiwan; ${ }^{5}$ Division of Pulmonary and Critical Care Medicine, Department of Internal Medicine, China Medical University Hospital, Taichung, Taiwan. Correspondence: Yu-Fen Li (yufenli@mail.cmu.edu.tw) 
Table 1. Demographics between children with and without asthma

\begin{tabular}{lccc}
\hline & $\begin{array}{c}\text { Nonasthma } \\
(n=1,006,791)\end{array}$ & $\begin{array}{c}\text { Asthma } \\
(n=251,698)\end{array}$ & \\
\cline { 2 - 3 } & $n(\%)$ & $n(\%)$ & P value \\
\hline Age, years, mean (SD) & $4.50(3.44)$ & $4.49(3.42)$ & 0.58 \\
Stratified age & & & \\
$\leq 2$ & $240,832(23.9)$ & $60,208(23.9)$ & 0.99 \\
$2-5$ & $439,448(43.7)$ & $109,862(43.7)$ & \\
5-12 & $279,471(27.8)$ & $69,868(27.8)$ & \\
$>12$ & $47,040(4.67)$ & $11,760(4.67)$ & \\
Gender & & & \\
Girl & & & \\
Boy & $408,459(40.6)$ & $102,115(40.6)$ & 0.99 \\
Urbanization & $598,332(59.4)$ & $149,583(59.4)$ & \\
1 (highest) & & & \\
2 & $294,899(29.3)$ & $73,725(29.3)$ & 0.99 \\
3 & $307,212(30.5)$ & $76,803(30.5)$ & \\
4(lowest) & $186,996(18.6)$ & $46,749(18.6)$ & \\
Occupation & $217,684(21.6)$ & $54,421(21.6)$ & \\
White collar & & & \\
Blue collar & $650,339(64.6)$ & $162,585(64.6)$ & \\
Others & $244,612(24.3)$ & $61,153(24.3)$ & \\
\hline
\end{tabular}

Chi-square test, ${ }^{\text {t}}$-test.

risk of INS in the asthma cohort increased from 1.49 (95\% CI: 1.06-2.11) for those with $\leq 3$ visits to 15.7 (95\% CI: 11.5-21.4) for those with $\geq 6$ visits (trend test, $P<0.0001)$. The risk was similar for both sexes. Asthmatic subjects with $>6$ medical visits had a significantly lower INS-free survival rate than the subjects in the nonasthma cohort (Figure 1b; log-rank test, $P<0.0001)$.

Table 4 presents the risk of INS stratified by median followup duration. The risk of INS was greater among subjects in the asthma cohort followed up for $\leq 5.5$ y (HR $=3.41$; 95\% CI: $2.66-$ $4.38)$, whereas the risk of INS slightly decreased ( $\mathrm{HR}=2.90$; 95\% CI: 1.33-6.30) among the subjects with a $>5.5-y$ follow-up duration. However, the association between asthma status and follow-up period was not significant $(P=0.91)$.

\section{DISCUSSION}

To our knowledge, this is the first population-based cohort study to investigate the incidence and risk of INS among children with asthma and compare them with the nonasthmatic controls. The results suggest that children with asthma were more likely to develop INS regardless of sex, age, urbanization of living area, or parental occupation. The annual incidence of NS in children in the United States and in Europe has been estimated to be $1-7$ per 100,000 children $(1,23)$. The present study revealed an incidence rate of 2.76 of 100,000 personyears in the nonasthma cohort and a significantly increased incidence rate of 9.21 of 100,000 person-years in the asthma cohort. Although the definition of INS in current study was
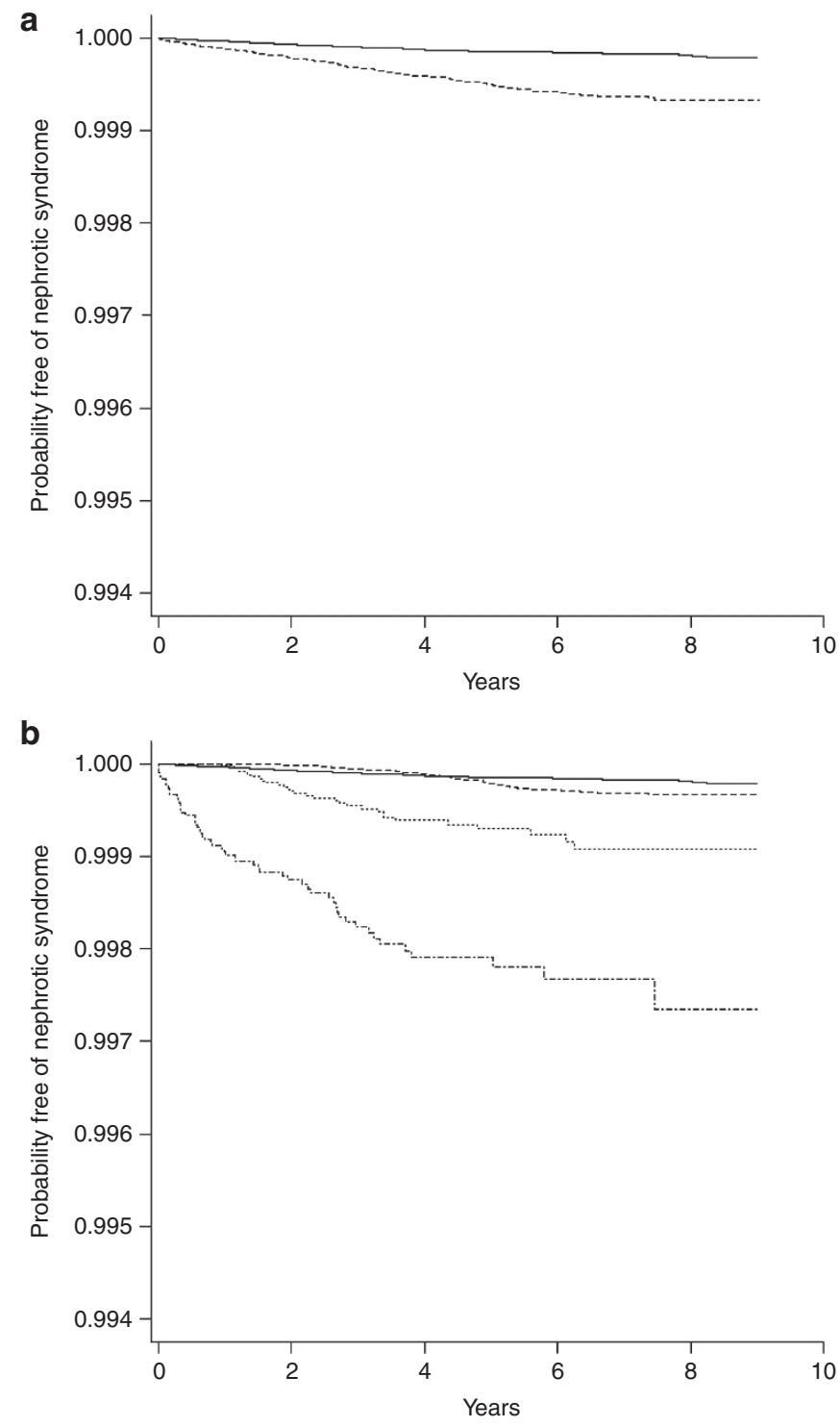

Figure 1. Probability of event free (onset of idiopathic nephrotic syndrome) survival. (a) In children with and without asthma. - Without asthma; --- With asthma. (b) In different frequency of annual asthma-related medical visits. - Without asthma; ---With $<4$ asthma-related medical visits; ...With 4-6 asthma-related medical visits with $>6$ asthma-related medical visits.

based on ICD9 codes, not on histopathology findings, the incidence rate of INS was comparable to previous results. In addition, the incidence rate ratio increased with more medical visits for asthma and school-age children with asthma.

In the current study, the incidence rate of INS decreased as age increased in nonasthma controls, that ranged from 3.53 per 100,000 person-years for children aged $\leq 2$ y to 1.89 per 100,000 person-years for children aged $>12 \mathrm{y}$. As the peak incidence of childhood INS is known between 2 and $6 y$ of age, this was reflected by the higher incidence rate of INS in the younger children in the nonasthma controls. In contrary contrast, the incidence rate ratio (HR) of INS increased as age increased in the asthma cohorts compared to nonasthma controls, that ranged from 2.89 (95\% CI: $1.87-4.47$ ) for children aged $\leq 2 \mathrm{y}$ 
Table 2. The incidence rate and relative risk of idiopathic nephrotic syndrome in asthma children compared to non-asthma children stratified by demographics in Cox proportional hazard regression

\begin{tabular}{|c|c|c|c|c|c|c|c|}
\hline & \multicolumn{3}{|c|}{ Non- asthma } & \multicolumn{3}{|c|}{ Asthma } & \multirow[b]{2}{*}{$\mathrm{HR}(95 \% \mathrm{Cl})$} \\
\hline & NS case & Person-years & IR & NS case & Person-years & IR & \\
\hline All & 149 & $5,396,842$ & 2.76 & 126 & $1,360,811$ & 9.26 & $3.36(2.65,4.26)^{*}$ \\
\hline \multicolumn{8}{|l|}{ Age group } \\
\hline$\leq 2$ & 48 & $1,358,256$ & 3.53 & 35 & 344,068 & 10.20 & $2.89(1.87,4.47)^{*}$ \\
\hline $2-5$ & 59 & $2,238,316$ & 2.64 & 49 & 563,545 & 8.69 & $3.30(2.26,4.82)^{*}$ \\
\hline $5-12$ & 37 & $1,535,649$ & 2.41 & 35 & 386,805 & 9.05 & $3.76(2.37,5.97)^{*}$ \\
\hline$>12$ & 5 & 264,620 & 1.89 & 7 & 66,394 & 10.50 & $5.59(1.77,17.6)^{*}$ \\
\hline \multicolumn{8}{|l|}{ Gender } \\
\hline Girl & 52 & $2,177,123$ & 2.39 & 50 & 548,921 & 9.11 & $3.82(2.59,5.64)^{*}$ \\
\hline Boy & 97 & $3,219,719$ & 3.01 & 76 & 811,890 & 9.36 & $3.12(2.31,4.21)^{*}$ \\
\hline \multicolumn{8}{|l|}{ Urbanization } \\
\hline 1 (highest) & 39 & $1,573,053$ & 2.48 & 27 & 397,137 & 6.80 & $2.75(1.68,4.49)^{*}$ \\
\hline 2 & 40 & $1,640,310$ & 2.44 & 33 & 413,698 & 7.98 & $3.28(2.07,5.20)^{*}$ \\
\hline 3 & 38 & $1,006,851$ & 3.77 & 27 & 253,779 & 10.60 & $2.83(1.73,4.63)^{*}$ \\
\hline 4 (lowest) & 32 & $1,176,627$ & 2.72 & 39 & 296,197 & 13.20 & $4.85(3.04,7.74)^{*}$ \\
\hline \multicolumn{8}{|c|}{ Parental occupation } \\
\hline White collar & 99 & $3,461,276$ & 2.86 & 76 & 872,850 & 8.71 & $3.05(2.26,4.11)^{*}$ \\
\hline Blue collar & 32 & $1,362,334$ & 2.35 & 34 & 342,807 & 9.92 & $4.23(2.61,6.86)^{*}$ \\
\hline Others & 18 & 573,231 & 3.14 & 16 & 145,155 & 11.00 & $3.52(1.80,6.91)^{*}$ \\
\hline
\end{tabular}

HR, hazard ratio; IR, incidence rate, per 100,000 person-years.

${ }^{*} P<0.001$

to 5.59 (95\% CI: $1.77-17.6$ ) for children aged $>12 \mathrm{y}$. This result may be explained as follows. Asthma is currently considered a heterogeneous disease (24). Three main phenotypes have been identified in childhood asthma, including transient wheezing, nonatopic wheezing, and IgE-mediated wheezing (allergic asthma) (24). Transient wheezing phenotype typically begins in early infancy and resolves between the ages of 3-5 y when their lung function improves. This phenotype is not commonly associated with atopy. Nonatopic wheezers wheeze during the first decade of life in association with respiratory viral infection, independent of allergic sensitization. This phenotype usually presents with less severe and less persistent wheeze. Only IgE-mediated wheezing has been identified as the classic asthma phenotype (persistent asthma) with higher disease severity. The proportion of allergic asthma is higher in older children (school aged children) (24). School aged children had a higher risk of INS, as allergic asthma is more prevalent in school-aged children, the higher prevalence of INS seen in this age group was therefore consistent with an association between INS and allergic asthma. In addition, we also found children with more asthma-related visits per year had greater risk of INS, which may reflect the association between INS risk and uncontrolled airway inflammation, more severe and persistent phenotype of asthma or more environmental triggers, such as allergen exposure or respiratory virus in asthma children $(25,26)$. Moreover, greater risk of INS was observed within the first $5.5 \mathrm{y}$ after asthma diagnosis. This may be explained as follows. First, childhood asthma may resolve over times, especially in phenotypes of transient wheezing and nonatopic wheezing. Second, older children have less frequency of viral respiratory tract infections. Third, the asthma related airway inflammation and respiratory symptoms may be controlled with adequate treatment over times. Overall, the implication of above findings suggests that a higher burden of clinically evident asthma symptoms is associated with the risk of INS.

A possible link between INS and allergy has been reported for $>50$ y (2-10). Before 1970s, only anecdotal reports described patients who developed INS after allergic events to certain allergens (2-5). Since 1970, several case-control studies revealed that elevated serum IgE were more common in children with INS compared to normal controls $(9,11-17,27)$. Subsequently, the levels of $\mathrm{T}$ helper 2-associated cytokines such as interleukin (IL)-4 and IL-13 were found to be upregulated in relapsing INS patients (19-21). IL-4 and IL-13 are important in B-cell IgE isotype switching (28), and IL-13 is also involved in the modulation of eosinophilic inflammation and recruitment of monocytes and T cells (28). The release of IgE by B cells is a key step in the allergic inflammation cascade in allergic asthma (28). Recently, minimal change disease (MCD) is proposed to be a podocyte disorder. Reiser et al. reported that CD80 (also known as B7.1), a receptor normally expressed on antigen-presenting cells $(29,30)$, can be induced expression in podocytes which is associated with actin reorganization and the development 
of proteinuria $(31,32)$. Then, Garin et al. found children with biopsy proven MCD expressed CD80 in their podocytes and excreted high levels of CD80 in their urine during active nephrotic syndrome $(33,34)$. Following these results, they reported sera from MCD patients in relapse stimulates CD80 expression in cultured podocytes (35). In addition, increased CD80 expression in podocyte, glomerular CD80 and urinary excretion of CD80 can be induced by polyIC, a Toll-like receptor 3 ligand, and were associated with proteinuria (36). It implies the important role of CD80 in the pathogenesis of MCD. Asthma is a Th2-mediated disease (37). Airway dendritic cells activate naive $\mathrm{T}$ cells to generate $\mathrm{Th} 2$ cells through costimulatory molecules, CD80/CD86, interacting with CD28 and cytotoxic T lymphocyte-associated antigen 4 after allergic triggers in the inception of asthma (37-39). These common biologic mechanisms coexisting in both asthma and INS may partly explain the complex relationship between these two diseases.

Table 3. The risk of idiopathic nephrotic syndrome stratified by the frequency of asthma-related medical visits per year by Cox proportional hazard regression

\begin{tabular}{|c|c|c|c|c|}
\hline $\begin{array}{l}\text { Frequency of visits per } \\
\text { year }\end{array}$ & $\begin{array}{l}\text { NS } \\
\text { case }\end{array}$ & $\begin{array}{c}\text { Person- } \\
\text { years }\end{array}$ & IR & $\mathrm{HR}(95 \% \mathrm{Cl})$ \\
\hline \multicolumn{5}{|l|}{ All } \\
\hline No asthma & 149 & $5,396,842$ & 2.76 & 1.00 \\
\hline$\leq 3$ & 41 & $1,011,816$ & 4.05 & $1.49(1.06,2.11)^{*}$ \\
\hline $4-6$ & 30 & 228,350 & 13.10 & $4.59(3.10,6.80)^{* *}$ \\
\hline$>6$ & 55 & 120,645 & 45.60 & $15.70(11.5,21.4)^{* *}$ \\
\hline$P$ for trend & & & & $<0.0001$ \\
\hline \multicolumn{5}{|l|}{ Girl } \\
\hline No asthma & 52 & $2,177,123$ & 2.39 & 1.00 \\
\hline$\leq 3$ & 18 & 417,193 & 4.31 & $1.83(1.07,3.14)^{*}$ \\
\hline $4-6$ & 11 & 88,009 & 12.50 & $5.06(2.64,9.70)^{* *}$ \\
\hline$>6$ & 21 & 43,719 & 48.00 & $19.20(11.5,31.9)^{* *}$ \\
\hline$P$ for trend & & & & $<0.0001$ \\
\hline \multicolumn{5}{|l|}{ Boy } \\
\hline No asthma & 97 & $3,219,719$ & 3.01 & 1.00 \\
\hline$\leq 3$ & 23 & 594,623 & 3.87 & $1.31(0.83,2.06)$ \\
\hline $4-6$ & 19 & 140,341 & 13.50 & $4.33(2.65,7.09)^{* *}$ \\
\hline$>6$ & 34 & 76,926 & 44.20 & $13.90(9.40,20.6)^{* *}$ \\
\hline$P$ for trend & & & & $<0.0001$ \\
\hline
\end{tabular}

$H R$, hazard ratio; IR, incidence rate, per 100,000 person-years.

${ }^{*} P<0.05 ;{ }^{*} P<0.001$
Certain limitations should also be noted when interpreting our findings. Detailed information on clinical conditions (e.g., serum IgE level, severity of allergic symptoms, and environmental exposures) was not available. Furthermore, our study population included Chinese children; thus, our findings may not be generalizable to populations from other countries.

\section{Conclusion}

This population-based cohort study revealed a significantly increased incidence rate of INS in children with asthma. Further research is needed to explore the role of allergic diseases in the development of INS and to devise a potential strategy for diagnosis and therapeutic disease intervention.

\section{METHODS}

\section{Data Sources}

In this population-based, retrospective study, data were obtained from reimbursement claims of the universal National Health Insurance Research Database, which is maintained by the National Health Research Institute. We obtained claims data from 1998 through 2008 for all insured children in Taiwan and randomly selected $50 \%$ of these children for the study. Details regarding the data set were previously described (40). The International Classification of Disease, Ninth Revision, Clinical Modification (ICD-9-CM) was used to for diagnosis. Because of personal electronic data privacy regulations, the insurants' records are encrypted before being released to researchers; thus, informed consent was not required in this study. Although the identification information was scrambled, this study also received approval from the Institutional Review Board at China Medical University Hospital (CMU-REC-101-012).

\section{Study Subjects}

We identified patients aged $<18$ y with newly diagnosed asthma (ICD9-CM codes 493 and 494) between 2000 and 2007 as the asthma cohort. Baseline was set as the date of asthma diagnosis. In this study, we used the method of " $1: 4$ " matching to screen the control subjects, which can increase the statistical power and control the potential confounding. Hence, we randomly selected four nonasthmatic children for every asthmatic child using frequency matching by sex, age (in 1-y intervals), urbanization of residential area, parental occupation, and baseline year. To improve diagnostic accuracy and avoid overestimation of incidence, children with INS or asthma were defined as at least three records with respective ICD-9-CM codes in any diagnosis field of inpatient claims or ambulatory claims. Since renal biopsy is usually not indicated for first presentation of childhood INS and empirical steroid treatment can be considered prior to kidney biopsy and in our previous study (40), the most common codings of children with INS was 581.9 (86.8\%, unspecific pathologic lesion in kidney), and MCD (581.3). Therefore, INS was defined as ICD-9-CM code 581.3 and 581.9 in this study. Subjects with secondary nephrotic syndrome (NS), identified with an ICD-9-CM code 581.8, were excluded from the study. Subjects with a history of NS before baseline or those lacking information on age, sex, urbanization of residence area, or parental occupation were excluded. All subjects were followed up until INS diagnosis, death, loss to follow-up, withdrawal from the insurance system, or the end of 2008 .

Table 4. The risk of idiopathic nephrotic syndrome stratified by follow-up years

\begin{tabular}{|c|c|c|c|c|c|c|c|}
\hline Follow-up time & \multicolumn{3}{|c|}{ Nonasthma } & \multicolumn{3}{|c|}{ Asthma } & $\mathrm{HR}(95 \% \mathrm{Cl})$ \\
\hline$\leq 5.5 y$ & 134 & $4,472,283$ & 3.00 & 115 & $1,124,457$ & 10.20 & $3.41(2.66,4.38)^{*}$ \\
\hline
\end{tabular}

HR, hazard ratio; IR, incidence rate, per 100,000 person-years

aThe follow-up time is partitioned into two segments (years $\leq 5.5$, and $>5.5$ y) by median. ${ }^{*} P<0.001$ 


\section{Statistical Analysis}

In this cohort study, we used the person-years to be the denominator for estimating the incidence rate under considering about the individual follow-up duration in the study. The date of diagnosis of asthma was defined as the index date used to initiate follow-up person-years measurement. The follow-up person-years were measured for each child from the index date to the date the children had the diagnosis of INS, or censored because of loss to follow-up, or death, or withdraw from the insurance system, or the end of 2008. Follow-up person-years were used to estimate the incidence density rates (IR) and hazard ratios (HRs) of INS for the asthma cohort, which were compared with those of the non-asthma cohort based on age, sex, urbanization, and parental occupation. Hazard ratio was determined using the Cox proportional hazard regression model. The Cox model was also used to estimate the HR of INS associated with the annual mean medical visits for asthma. Furthermore, we analyzed if the association varied with the length of the followup period after asthma diagnosis. We divided the median followup time into two periods after asthma diagnosis: $\leq 5.5 \mathrm{y}$ and $>5 \mathrm{y}$. A Kaplan-Meier plot showed the probability of INS-free survival, and the log-rank test was used to test the difference between the asthma and non-asthma cohorts. We performed all data analyses using the SAS statistical software (version 9.2 for Windows; SAS Institute, Cary, NC). Kaplan-Meier survival curves were plotted using the R software (version 2.14.1; R Development Core Team, Vienna, Austria). A two-sided $P$ value $<0.05$ was considered statistically significant.

\section{ACKNOWLEDGMENTS}

C.-C.W. and T.-C.S. conceptualized and designed the study, drafted the manuscript, and approved the final manuscript as submitted. C.-L.L. conducted the initial analyses, reviewed and revised the manuscript, and approved the final manuscript as submitted. C.-C.W. and Y.-F.L. coordinated and supervised the data collection, critically reviewed the manuscript, and approved the final manuscript as submitted.

\section{STATEMENT OF FINANCIAL SUPPORT}

The study was supported in part by China Medical University Hospital (DMR-103-036); Taiwan Ministry of Health and Welfare Clinical Trial and Research Center of Excellence (MOHW104-TDU-B-212-113002); China Medical University Hospital, Academia Sinica Taiwan Biobank, Stroke Biosignature Project (BM104010092); NRPB Stroke Clinical Trial Consortium (MOST 103-2325-B-039 -006); Tseng-Lien Lin Foundation, Taichung, Taiwan; Taiwan Brain Disease Foundation, Taipei, Taiwan; and Katsuzo and Kiyo Aoshima Memorial Funds, Japan.

Disclosure: The authors have indicated that they have no financial relationships relevant to this article to disclose.

\section{REFERENCES}

1. Nephrotic syndrome in children: prediction of histopathology from clini$\mathrm{cal}$ and laboratory characteristics at time of diagnosis. A report of the International Study of Kidney Disease in Children. Kidney Int 1978;13:159-65.

2. Hardwicke J, Soothill JF, Squire JR, Holti G. Nephrotic syndrome with pollen hypersensitivity. Lancet 1959;1:500-2.

3. Wittig HJ, Goldman AS. Nephrotic syndrome associated with inhaled allergens. Lancet 1970;1:542-3.

4. Reeves WG, Cameron JS, Johansson SG, Ogg CS, Peters DK, Weller RO. Seasonal nephrotic syndrome. Description and immunological findings. Clin Allergy 1975;5:121-37.

5. Meadow SR, Sarsfield JK. Steroid-responsive and nephrotic syndrome and allergy: clinical studies. Arch Dis Child 1981;56:509-16.

6. Meadow SR, Sarsfield JK, Scott DG, Rajah SM. Steroid-responsive nephrotic syndrome and allergy: immunological studies. Arch Dis Child 1981;56:517-24.

7. Rebien W, Müller-Wiefel DE, Wahn U, Schärer K. IgE mediated hypersensitivity in children with idiopathic nephrotic syndrome. Int J Pediatr Nephrol 1981;2:23-8.
8. Yap HK, Yip WC, Lee BW, et al. The incidence of atopy in steroidresponsive nephrotic syndrome: clinical and immunological parameters. Ann Allergy 1983;51:590-4.

9. Lin CY, Lee BH, Lin CC, Chen WP. A study of the relationship between childhood nephrotic syndrome and allergic diseases. Chest 1990;97: 1408-11.

10. Florido JF, Díaz Pena JM, Belchi J, Estrada JL, García Ara MC, Ojeda JA. Nephrotic syndrome and respiratory allergy in childhood. J Investig Allergol Clin Immunol 1992;2:136-40.

11. Groshong T, Mendelson L, Mendoza S, Bazaral M, Hamburger R, Tune B. Serum IgE in patients with minimal-change nephrotic syndrome. J Pediatr 1973;83:767-71.

12. Schulte-Wissermann H, Görtz W, Straub E. IgE in patients with glomerulonephritis and minimal-change nephrotic syndrome. Eur J Pediatr 1979;131:105-11.

13. Lagrue G, Laurent J, Hirbec G, et al. Serum IgE in primary glomerular diseases. Nephron 1984;36:5-9.

14. Shu KH, Lian JD, Yang YF, Lu YS, Wang JY. Serum IgE in primary glomerular diseases and its clinical significance. Nephron 1988;49:24-8.

15. Mansfield LE, Trygstad CW, Ajugwo RE, Heiner DC. Serum concentrations of immunoglobulins $\mathrm{E}$ and $\mathrm{G}$ and alpha 2-macroglobulin in childhood renal disease. J Allergy Clin Immunol 1980;66:227-32.

16. Tain YL, Chen TY, Yang KD. Implication of serum IgE in childhood nephrotic syndrome. Pediatr Nephrol 2003;18:1211-5.

17. Hu JF, Liu YZ. Elevated serum IgE levels in children with nephrotic syndrome, a steroid-resistant sign? Nephron 1990;54:275.

18. Eddy AA, Symons JM. Nephrotic syndrome in childhood. Lancet 2003;362:629-39.

19. Cho BS, Yoon SR, Jang JY, Pyun KH, Lee CE. Up-regulation of interleukin-4 and CD23/FcepsilonRII in minimal change nephrotic syndrome. Pediatr Nephrol 1999;13:199-204.

20. Kimata H, Fujimoto M, Furusho K. Involvement of interleukin (IL)-13, but not IL-4, in spontaneous IgE and IgG4 production in nephrotic syndrome. Eur J Immunol 1995;25:1497-501.

21. Yap HK, Cheung W, Murugasu B, Sim SK, Seah CC, Jordan SC. Th1 and Th2 cytokine mRNA profiles in childhood nephrotic syndrome: evidence for increased IL-13 mRNA expression in relapse. J Am Soc Nephrol 1999;10:529-37.

22. Masoli M, Fabian D, Holt S, Beasley R; Global Initiative for Asthma (GINA) Program. The global burden of asthma: executive summary of the GINA Dissemination Committee report. Allergy 2004;59:469-78.

23. McKinney PA, Feltbower RG, Brocklebank JT, Fitzpatrick MM. Time trends and ethnic patterns of childhood nephrotic syndrome in Yorkshire, UK. Pediatr Nephrol 2001;16:1040-4.

24. Stein RT, Martinez FD. Asthma phenotypes in childhood: lessons from an epidemiological approach. Paediatr Respir Rev 2004;5:155-61.

25. Sullivan SD, Rasouliyan L, Russo PA, Kamath T, Chipps BE; TENOR Study Group. Extent, patterns, and burden of uncontrolled disease in severe or difficult-to-treat asthma. Allergy 2007;62:126-33.

26. Strachan DP. The role of environmental factors in asthma. Br Med Bull 2000;56:865-82.

27. Gerber MA, Paronetto F. IgE in glomeruli of patients with nephrotic syndrome. Lancet 1971;1:1097-9.

28. Galli SJ, Tsai M, Piliponsky AM. The development of allergic inflammation. Nature 2008;454:445-54.

29. Linsley PS, Clark EA, Ledbetter JA. T-cell antigen CD28 mediates adhesion with B cells by interacting with activation antigen B7/BB-1. Proc Natl Acad Sci USA 1990;87:5031-5.

30. Abbas AK, Sharpe AH. T-cell stimulation: an abundance of B7s. Nat Med 1999;5:1345-6.

31. Reiser J, Mundel P. Danger signaling by glomerular podocytes defines a novel function of inducible B7-1 in the pathogenesis of nephrotic syndrome. J Am Soc Nephrol 2004;15:2246-8.

32. Reiser J, von Gersdorff G, Loos M, et al. Induction of B7-1 in podocytes is associated with nephrotic syndrome. J Clin Invest 2004;113:1390-7. 
33. Garin $\mathrm{EH}, \mathrm{Mu} \mathrm{W}$, Arthur JM, et al. Urinary CD80 is elevated in minimal change disease but not in focal segmental glomerulosclerosis. Kidney Int 2010;78:296-302.

34. Garin EH, Diaz LN, Mu W, et al. Urinary CD80 excretion increases in idiopathic minimal-change disease. J Am Soc Nephrol 2009;20: 260-6.

35. Ishimoto T, Cara-Fuentes $\mathrm{G}$, Wang $\mathrm{H}$, et al. Serum from minimal change patients in relapse increases CD80 expression in cultured podocytes. Pediatr Nephrol 2013;28:1803-12.

36. Ishimoto T, Shimada M, Gabriela G, et al. Toll-like receptor 3 ligand, polyIC, induces proteinuria and glomerular CD80, and increases urinary CD80 in mice. Nephrol Dial Transplant 2013;28:1439-46.
37. Chen YQ, Shi HZ. CD28/CTLA-4-CD80/CD86 and ICOS-B7RP-1 costimulatory pathway in bronchial asthma. Allergy 2006;61:15-26.

38. van Rijt LS, Vos N, Willart M, et al. Essential role of dendritic cell CD80/ CD86 costimulation in the induction, but not reactivation, of TH2 effector responses in a mouse model of asthma. J Allergy Clin Immunol 2004;114:166-73.

39. Balbo P, Silvestri M, Rossi GA, Crimi E, Burastero SE. Differential role of CD80 and CD86 on alveolar macrophages in the presentation of allergen to T lymphocytes in asthma. Clin Exp Allergy 2001;31:625-36.

40. Wei CC, Yu IW, Lin HW, Tsai AC. Occurrence of infection among children with nephrotic syndrome during hospitalizations. Nephrology (Carlton) 2012;17:681-8. 